\title{
Complete heart block in ankylosing spondylitis
}

\author{
Juan Pablo Restrepo ${ }^{1}$, María Del Pilar Molina ${ }^{2}$
}

\begin{abstract}
Ankylosing spondylitis (AS) is a chronic rheumatic disease of young men that affects mainly the axial skeleton and is associated with HLA-B27 in 90\% of the cases. Incidence of cardiovascular involvement in AS ranges between 10\%-30\%; conduction disturbances have been described in $1 \%-9 \%$ of the patients with AS. The majority of the series show a relationship with longstanding disease. To our knowledge, this is the first report of complete heart block in early AS.
\end{abstract}

Keywords: ankylosing spondylitis, HLA-B27 antigen, heart block.

(C) 2012 Elsevier Editora Ltda. All rights reserved.

\section{INTRODUCTION}

Ankylosing spondylitis (AS) is a chronic rheumatic disease of young men that affects mainly axial skeleton and is associated with HLA-B27 in $90 \%$ of the cases. Cardiovascular manifestations can occur in patients with chronic disease. We describe a 22-year-old man who presented complete heart block associated to AS.

\section{CASE REPORT}

A 22-year-old Colombian male otherwise healthy presented with insidious onset of low back pain improved by exercise and not relieved by rest over 1.5 years. He had been treated with nonsteroidal anti-inflammatory drugs (NSAIDs) for several months with no response. His initial Bath Ankylosing Spondylitis Disease Activity Index (BASDAI) and Bath Ankylosing Spondylitis Metrology Index (BASMI) were 4.8 and 2, respectively. The sacroiliac X-rays showed a bilateral sacroiliitis grade 3 (Figure 1) and HLA-B27 was positive. The patient denied skin, ocular, bowel, and genitourinary associated disease. A diagnosis of AS was done based on modified New York classification criteria for AS. ${ }^{1}$ Adalimumab was initiated at the conventional dose and six months later the patient had total resolution of his main complaint. Two months ago he had a syncopal episode; during his hospitalization a resting electrocardiography was performed detecting a complete atrioventricular block (Figure 2); echocardiogram and laboratory tests were normal, with implantation of a DDD-R pacemaker. The patient now has a BASDAI of 0.4, BASMI of 2 and is completely asymptomatic.

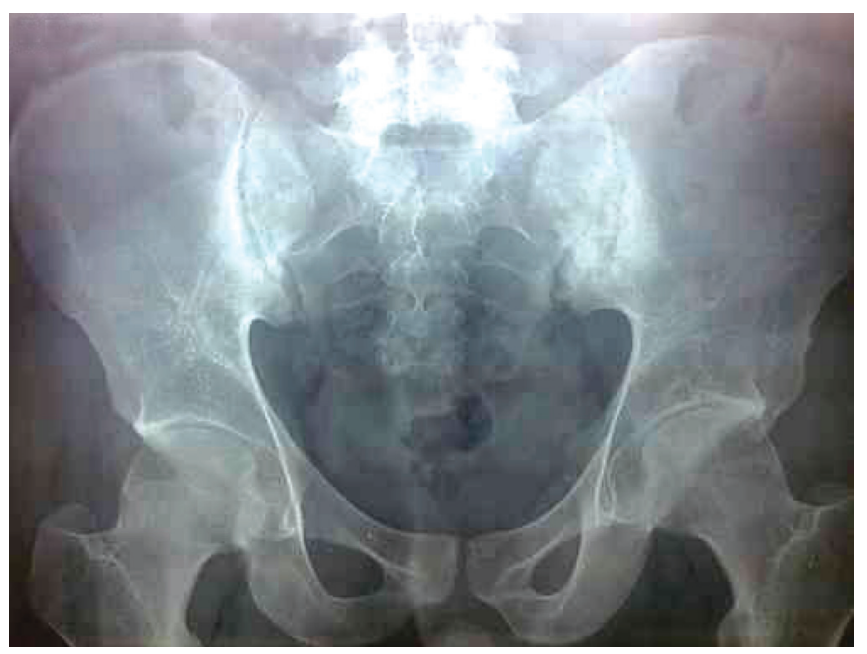

Figure 1

Bilateral sacroiliitis grade 3 .

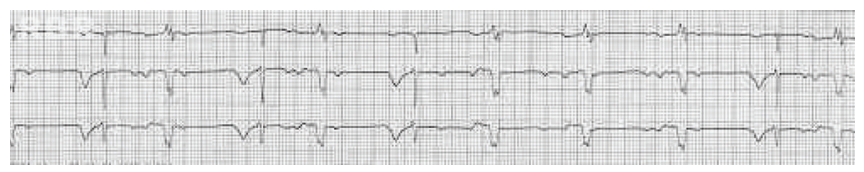

Figure 2

Surface electrocardiogram showing complete atrioventricular block with ventricular ectopic beats.

1. Rheumatologist; Professor, Universidad del Quindío

2. General Practitioner

Correspondence to: Juan Pablo Restrepo. Cra 13 No 1-35, consultorio 412, Armenia. Quindío, Colombia. E-mail: jprestrepo@lycos.com 


\section{DISCUSSION}

AS is a chronic rheumatic disease of young men that affects mainly the axial skeleton and is associated with HLA-B27 in $90 \%$ of the cases. ${ }^{2}$ Incidence of cardiovascular involvement in AS ranges between $10 \%-30 \%{ }^{3}$ The most common lesions include aortitis, aortic valvular incompetence, and conduction disturbances. In the latter group can be observed atrioventricular blocks, bundle branch blocks, and intraventricular blocks. Atrioventricular conduction blocks have been found in 1\%-9\% of patients with AS. ${ }^{4}$ Initially they appear in an intermittent manner and could progress to complete and definitive atrioventricular block. Ninety-nine percent of patients with cardiac complications are male. ${ }^{5}$

There seems to be a relationship between a definitive pacemaker implantation and positive results for HLA-B27. It was found that $15 \%-20 \%$ of patients with definitive pacemaker implantation were HLA-B27-positive. ${ }^{6}$ Two complementary theories may explain the conduction disturbances: anomalies in the atrioventricular nodal artery and inflammation in the intraventricular septum. ${ }^{7}$ The risk of cardiac complications increases with age of patient, duration of AS, presence of HLA-B27, and peripheral joint involvement. ${ }^{8}$ Cardiovascular features typically occur in longstading AS. Kinsella et al. ${ }^{9}$ reported a mean duration of AS of 21 years; the Brunner group reported a mean duration of 33 years..$^{10}$ Confirming previous findings, Dik et al. found no second/third degree atrioventricular block after up to 11 years of follow-up. ${ }^{11}$ This group defined as "early" an AS with diagnosis duration of less than two years. Our case report suggests cardiac monitoring in early stages of AS subgroup HLA-B27-positive in order to possibly diagnose conduction disturbances. 


\section{REFERENCES}

1. van der Linden S, Valkenburg H, Cats A. Evaluation of the diagnostic criteria for ankylosing spondylitis: a proposal for modification of the New York criteria. Arthritis Rheum 1984; 27(4):361-8.

2. Peeters A, ten Wolde S, Sedney M, de Vries RR, Dijkmans BA. Heart conduction disturbance: an HLA-B27 associated disease. Ann Rheum Dis 1991; 50(6):348-50.

3. Kazmierczak J, Peregud-Pogorzelska M, Biernawska J, PrzepieraBedzak H, Goracy J, Brzosko I et al. Cardiac arrhythmias and conduction disturbances in patients with ankylosing spondylitis. Angiology 2008; 58(6):751-6.

4. Bergfeldt L. HLA B27-associated cardiac disease. Ann Intern Med 1997; 127(8 Pt 1):621-9.

5. Sukenik S, Pras A, Buskila D, Katz A, Snir Y, Horowitz J. Cardiovascular manifestations of ankylosing spondylitis. Clin Rheumatol 1987; 6(4):588-92.

6. Bergfeldt L, Vallin H, Edhag O. Complete heart block in HLA B27 associated disease. Electrophysiological and clinical characteristics. Br Heart J 1984; 51(2):184-8.

7. Momeni N, Taylor N, Tehrani M. Cardiopulmonary manifestations of ankylosing spondylitis. Int J Rheumatol 2011; 2011:728471.

8. Ulusoy V, Ateş A, Çiçekcioğlu H, Acvioğlu Y, Karaaslan Y. Thirddegree heart block developing in a female patient with HLA-B27 positive ankylosing spondylitis. Rheumatol Int 2006; 26(8):779-80.

9. Kinsella D, Johnson L, Ian R. Cardiovascular manifestations of ankylosing spondylitis. Can Med Assoc J 1974; 111(12):1309-11.

10. Brunner F, Kunz A, Weber U, Kissling R. Ankylosing spondylitis and heart abnormalities: do cardiac conduction disorders, valve regurgitation and diastolic dysfunction occur more often in male patients with diagnosed ankylosing spondylitis for over 15 years than in the normal population? Clin Rheumatol 2006; 25(1):24-9.

11. Dik V, Peters M, Dijkmans P, Van der Weijden M, De Vries MK, Dijkmans BA et al. The relationship between disease-related characteristics and conduction disturbances in ankylosing spondylitis. Scand J Rheumatol 2010; 39(1):38-41. 